\title{
Effect of spatial distribution of daily rainfall on interior catchment response of a distributed hydrological model
}

\author{
J. M. Schuurmans ${ }^{1}$ and M. F. P. Bierkens ${ }^{1,2}$ \\ ${ }^{1}$ Department of Physical Geography, Faculty of Geosciences, Utrecht University, P.O. Box 80115, 3508 TC, Utrecht, The \\ Netherlands \\ ${ }^{2}$ TNO Built Environment and Geosciences, P.O. Box 80015, 3508 TA Utrecht, The Netherlands
}

Received: 26 June 2006 - Published in Hydrol. Earth Syst. Sci. Discuss.: 9 August 2006

Revised: 20 November 2006 - Accepted: 13 December 2006 - Published: 17 January 2007

\begin{abstract}
We investigate the effect of spatial variability of daily rainfall on soil moisture, groundwater level and discharge using a physically-based, fully-distributed hydrological model. This model is currently in use with the district water board and is considered to represent reality. We focus on the effect of rainfall spatial variability on day-to-day variability of the interior catchment response, as well as on its effect on the general hydrological behaviour of the catchment. The study is performed in a flat rural catchment $\left(135 \mathrm{~km}^{2}\right)$ in the Netherlands, where the climate is semi-humid (average precipitation $800 \mathrm{~mm} /$ year, evapotranspiration $550 \mathrm{~mm} /$ year) and rainfall is predominantly stratiform (i.e. large scale). Both range-corrected radar data (resolution $2.5 \times 2.5 \mathrm{~km}^{2}$ ) as well as data from a dense network of 30 raingauges are used, observed for the period March-October 2004. Eight different rainfall scenarios, either spatially distributed or spatially uniform, are used as input for the hydrological model. The main conclusions from this study are: (i) using a single raingauge as rainfall input carries a great risk for the prediction of discharge, groundwater level and soil moisture, especially if the raingauge is situated outside the catchment; (ii) taking into account the spatial variability of rainfall instead of using areal average rainfall as input for the model is needed to get insight into the day-to-day spatial variability of discharge, groundwater level and soil moisture content; (iii) to get insight into the general behaviour of the hydrological system it is sufficient to use correct predictions of areal average rainfall over the catchment.
\end{abstract}

\section{Introduction}

Rainfall is often defined as being the key variable in hydrological systems. Considering the question how the spa-

Correspondence to: J. M. Schuurmans

(h.schuurmans@geo.uu.nl) tial variability of rainfall influences the hydrological state, most studies have focussed on the effect on catchment discharge (e.g. Obled et al., 1994; Arnaud et al., 2002; Bell and Moore, 2000; Shah et al., 1991). Obled et al. (1994) conclude from their study (using TOPMODEL for a rural catchment of $71 \mathrm{~km}^{2}$ ) that the spatial variability must be taken into account more because it improves the estimation of the basin average incoming volume, rather than because of some dynamic interactions with flow-generating processes. Arnaud et al. (2002) (using 3 different rainfall-runoff models for 4 fictitious catchments of $20-1500 \mathrm{~km}^{2}$ ) however, found that rainfall variability can lead to significant different discharge, not for extreme events but for the more frequent events. This was also concluded by Shah et al. (1991): under "wet" conditions, good predictions of runoff can be obtained with a spatially averaged rainfall input but under "dry" conditions, spatial variability of rainfall has a significant influence. They suggest this is caused by the spatial distribution of soil moisture which controls the runoff production. Bell and Moore (2000) also show the importance of taking into account the spatial variability of rainfall, especially in case of convective rainfall events, which show high spatial variability. O'Connell and Todini (1996) point out the need to study the influence of space-time rainfall variability on the hydrological system in real catchments, but up to now not much attention has been given to the influence of rainfall variability on groundwater level and soil moisture content within the catchment.

A promising method to capture the variability of rainfall is meteorological radar. Real-time radar products are now readily available in many western countries in the world (e.g. Gekat et al., 2004; Krajewski and Smith, 2002; Carpenter et al., 2001). There is, however, only limited use of these products in operational hydrology. One of the reasons for this lack of use could be the uncertainty about the radar estimated rainfall field accuracy. Goodrich et al. (1995) noted that even though the spatial variability of rainfall may have significant influence on discharge, rainfall is usually assumed

Published by Copernicus GmbH on behalf of the European Geosciences Union. 
to be uniform in the application of hydrological models of small catchments. This is also the case in the Netherlands where often data from a single raingauge (even outside the catchment area) is used as input for hydrological model studies.

The main objective of our study is to determine how spatial variability of daily rainfall affects soil moisture, groundwater level and discharge as calculated by a physically-based, fully-distributed hydrological model. This is done for 2 purposes. First, to assess the effect of rainfall spatial variability on the day-to-day variability of the interior catchment response, i.e. to obtain a good insight in the current hydrological situation of a catchment, which is of great importance to water boards (e.g. operational water management) and agriculture (e.g. irrigation, sowing). Second, to assess its effect on the general behaviour of the hydrological system (e.g. average groundwater tables, water balance), which is important for planning strategies. A secondary objective is to determine how well operational radar products can capture the spatial variability of the daily rainfall for the purpose of hydrological modelling.

The study area is a rural catchment of $135 \mathrm{~km}^{2}$ in the middle of the Netherlands. For this study area an operational fully-distributed, physically based hydrological model is available from the controlling district water board. Also, operational radar images as well as data from a dense network of raingauges are available for the study area. Interpolated rainfall fields using data from the dense raingauge network as well as operational available radar and a combination of those two are used to describe the spatial variability of daily rainfall for the period March to October 2004. We consider daily rainfall as this is the time resolution for which the radar-estimated rainfall fields are range corrected in the Netherlands. We anticipate that for small mountainous catchments the spatio-temporal structures of rainfall fields are important, particular at small temporal aggregation. However, daily rainfall fields are sufficient for the Netherlands, because rainfall is predominantly stratiform and discharge is groundwater flow dominated. The different daily rainfall scenarios are used in a sensitivity analysis, i.e. as input for the hydrological model while comparing the calculated maps of groundwater level and soil moisture as well as the discharge hydrographs. We hypothesize that the sensitivity of the interior catchment response calculated by the model reflects the real interior catchment response. We only performed a sensitivity study and did not perform a separate calibration for each rainfall scenario. The reason is that we wanted to investigate solely the effect of different rainfall input on the outcomes of our hydrological model, while a calibration of the model parameters for each rainfall scenario would mask the effect of different input on the hydrological variables.

The characteristics of the catchment and the hydrological model are described in Sect. 2. In this section we also provide details about available rainfall data in the Netherlands. Section 3 deals with the way we analyzed the data, how we interpolated the raingauges and describes the rainfall scenarios we used. The results are given in Sect. 4, considering discharge, groundwater and soil moisture, while Sect. 5 concludes the paper with conclusions and discussion.

\section{Model and data}

\subsection{Study area}

The Lopikerwaard catchment $\left(135 \mathrm{~km}^{2}\right)$ is located in the middle of the Netherlands. Climate is semi-humid (average precipitation $800 \mathrm{~mm} /$ year, evapotranspiration $550 \mathrm{~mm} /$ year) and rainfall is predominantly stratiform (i.e. large scale). Figure 1a shows the exact location. The area is flat with a median surface level about $-1 \mathrm{~m}$ N.A.P. (reference sea level, Fig. 1b). Data about the surface level were extracted from the AHN (actual altitude database Netherlands), which is obtained by laser altimetry. The main soil type is alluvial clay deposited by rivers and peat. The main land use type is agricultural grassland (70\%). There are a few small villages in the area which in total occupy about $15 \%$ of the area (Fig. 1c). The Lopikerwaard is divided into four subcathments as shown in Fig. 1d, in which the area-size of each subcatchment is given in square kilometers. In each subcatchment groundwater levels are controlled by a dense network of drainage ditches where water levels are controlled by weirs and pumps. Four pumping stations (Keulevaart, Pleyt, Hoekse Molen, Koekoek) discharge the rainfall surplus to either the river Hollandse IJssel in the north or the river Lek in the south.

\subsection{Hydrological model}

Groundwater flow and soil moisture dynamics in the Lopikerwaard were modelled using the SIMGRO model code. We refer to Querner (1997) for more detailed information of SIMGRO. SIMGRO provides for physically based finite element modelling of regional groundwater flow in relation to drainage, water supply and water level control. SIMGRO based models simulate flow of water in the saturated zone, the unsaturated zone and the surface water network in an integrated manner.

In SIMGRO, the groundwater system is hydrogeologically schematized into a number of layers, with horizontal flow (Dupuit assumption) in water-conveying layers (aquifers) and vertical flow in less permeable layers (aquitards). Hydrogeological information, such as hydraulic transmissivity, vertical flow resistance, layer thickness, storage coefficient and porosity, is required for each layer. The boundary conditions for the aquifers can be either prescribed heads (Dirichlet condition) or prescribed fluxes (Neumann condition).

The flow of water in the unsaturated zone is described by a one-dimensional storage-output model. The unsaturated zone is considered to have two reservoirs; a root zone and an unsaturated zone in between the root zone and the saturated 


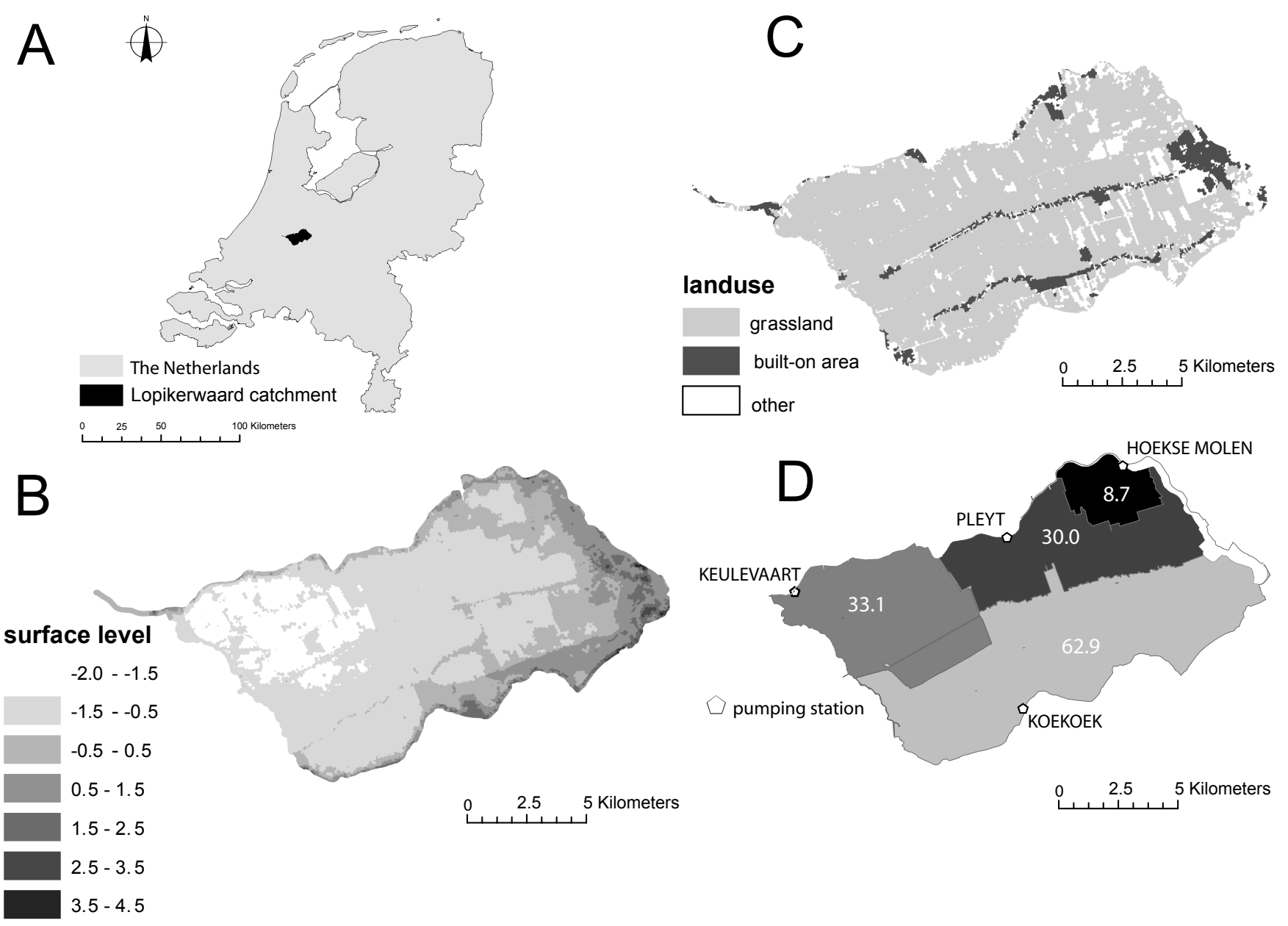

Fig. 1. (A) Location of Lopikerwaard catchment within the Netherlands; (B) Surface level of the Lopikerwaard catchment in meters + N.A.P. (reference sea level); (C) Land use in the Lopikerwaard catchment; (D) Subcatchments within the Lopikerwaard catchment with the corresponding pumping stations, area-size of each subcatchment is given in square kilometers.

zone. Transient flow is approximated by a series of steady states (pseudo dynamic simulation). The spatial discretization in finite elements defines the nodal subdomains. Within each nodal subdomain, the soil type and the type of land use must be defined. One nodal subdomain can have different types of land use but only one soil type. The combination of soil type and land use defines the thickness of the root zone and important characteristics of the unsaturated zone such as groundwater level dependent capillary rise, storage coefficient and field capacity. The calculated soil moisture is the amount of water in the root zone divided by the root zone thickness and is thus best comparable with volumetric soil moisture content.

The precipitation and Makkink reference evapotranspiration (Winter et al., 1995) are input variables for SIMGRO. The reference evapotranspiration is multiplied by a crop factor to obtain the potential evapotranspiration. The actual evaporation is calculated by SIMGRO as a linear function of the soil moisture state.
The Lopikerwaard model is an operational hydrological model that is used by the controlling district water board (Holleman et al., 2005). The Lopikerwaard model was schematized in SIMGRO using 17350 nodes. The model node distance is at maximum $150-200 \mathrm{~m}$. The existing drainage network was modelled using smaller node distances. The model was run for 12 years (1989-2001) and the model results were discussed with local experts from the water board (plausibility test). On the basis of this test some adjustments were made to the model. Hereafter, the model was calibrated on 3 parameters (storage coefficient, transmissivity and drainage resistance) using an automatic calibration technique (see Zaadnoordijk, 2003). This calibrated model was used for this study. We ran the model once for the period March-October 2004 (using one raingauge within the catchment as input) and the outcomes were set as the initial conditions of the subsequent model runs. 


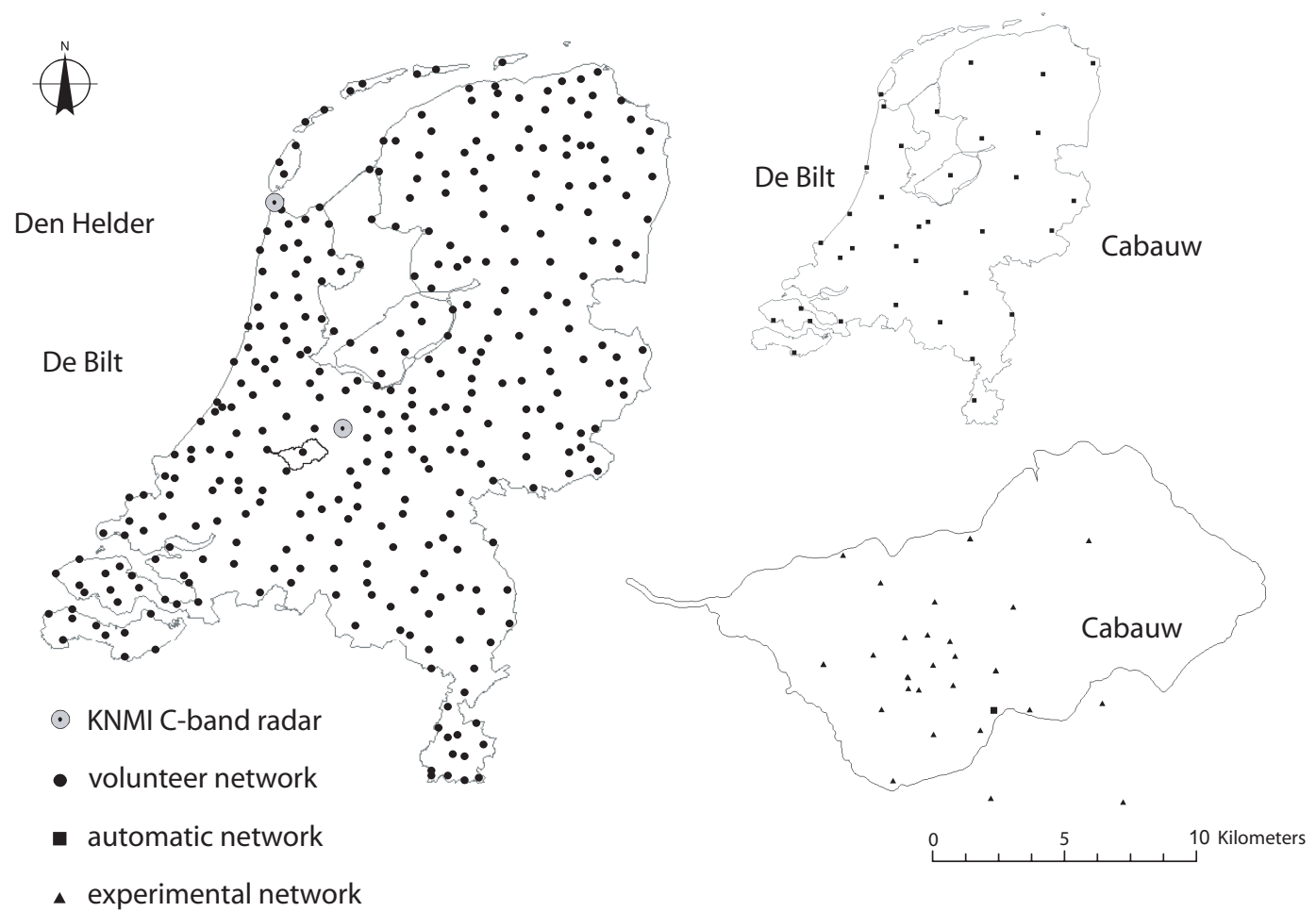

Fig. 2. Locations of raingauges and weather radars in the Netherlands; volunteer network with 330 raingauges (temporal resolution of 1 day), automatic network with 35 tipping bucket raingauges (temporal resolution of $10 \mathrm{~min}$ ), experimental network with 30 tipping bucket raingauges (equipped with event loggers) and $2 \mathrm{C}$-band Doppler radars.

\subsection{Meteorological input data}

\subsubsection{Raingauges}

In the Netherlands there are two permanent raingauge networks, which are operated by the Royal Netherlands Meteorological Institute (KNMI). The largest network consists of 330 stations and has a density of approximately 1 station per $100 \mathrm{~km}^{2}$. This network is maintained by volunteers who report daily rainfall depth at 08:00 UTC. An additional national network consists of 35 automatic raingauges and has a density of approximately 1 station per $1000 \mathrm{~km}^{2}$ and a temporal resolution of $10 \mathrm{~min}$. Within the catchment of interest, we maintained an experimental high-density network for almost 8 months, that consisted of 30 tipping bucket raingauges, all equipped with event loggers. The experimental network was set up to provide valuable information on the spatial structure of rainfall at short distances. For this study we mainly used our experimental network. Figure 2 shows the location of all the raingauges of the three networks.

\subsubsection{Radar}

The KNMI operates two C-band Doppler radars, one at De Bilt and one at Den Helder (Fig. 2), which both record
288 pseudo CAPPI $(800 \mathrm{~m})$ reflectivity fields each day (i.e. every $5 \mathrm{~min}$ ) after removal of ground clutter (Wessels and Beekhuis, 1997). The resolution of these fields is $2.5 \times 2.5 \mathrm{~km}^{2}$. The measured radar reflectivity factor $Z$ of each resolution unit is converted to surface rainfall intensity $R$ using the Marshall-Palmer Z- $R$ relationship, which has been found to be most suitable for stratiform dominated rainfall events (Battan, 1973):

$Z=200 \times R^{1.6}$

For both radars, the surface rainfall intensities are accumulated from 08:00 UTC until 08:00 UTC the next day, for each pixel. It is known that there is a distance-related underestimation of surface rainfall by weather radars due to spatial expansion of the radar beam and due to attenuation of the radar signal. Also overestimation due to the bright band (vertical profile of reflection) may occur. Therefore, data from the raingauges of the volunteer network, from the same period, are used to make a range correction for each radar separately every day (Holleman, 2004). After the range correction a composite field is constructed by averaging the pixel values of the two radars up to a radius of $200 \mathrm{~km}$ away from each radar. Within a radius of $15 \mathrm{~km}$ from one radar, the information of the other radar is used. This composite radar field is an operational product of the KNMI and is used in this study. 


\subsubsection{Evapotranspiration}

From the 35 stations with automatic raingauges (Fig. 2) also reference evapotranspiration data is available. The reference evapotranspiration is computed using the Makkink equation for grass (De Bruin, 1987), which is an empirical equation that requires only temperature and incoming short wave radiation. The data used in this study are $24 \mathrm{~h}$ accumulated reference evapotranspiration data over the period 00:00 UTC until 24:00 UTC, which is also an operational product of KNMI.

To adjust for the difference in accumulation period between the rainfall and evaporation data, we used evaporation data from one day earlier than the rainfall data. This can be justified by the fact that evaporation occurs mainly during daytime.

\section{Methods}

\subsection{Introduction}

We used 8 daily rainfall input scenarios for the period March to October 2004, of which 5 are spatially uniform and 3 are spatially variable rainfall fields. Details are given in Sect. 3.3. Using the 8 rainfall scenarios as input to the hydrological model we performed a sensitivity study on the output, i.e. the following variables:

- discharge: for all the pumping stations (Fig. 1) we analyzed the average daily discharge resulting from the different rainfall scenarios;

- groundwater: we analyzed the development of groundwater level in time for all nodes for each rainfall scenario. From these time series we selected 1 day with highly variable rainfall to study the spatial variability of groundwater level within the catchment;

- soil moisture: for soil moisture we performed the same analysis as for groundwater.

\subsection{Rainfall prediction}

For rainfall prediction on each model node, we used the geostatistical interpolation technique Kriging, which is based on the concept of random functions, whereby the unknown values are regarded as a set of spatially dependent random variables. For a theoretical description readers are referred to Isaaks and Srivastava (1989), Goovaerts (1997) and Cressie (1993).

For 74 daily rainfall events with mean rainfall depth of at least $1 \mathrm{~mm}$, we calculated the individual variograms of the standardized non-zero rainfall from the experimental network (Schuurmans et al., 2007). From these 74 individual variograms we also calculated the pooled variogram and fit- ted a spherical variogram model, which we used for the Kriging calculations:

$g(h)= \begin{cases}C_{0}\left(1-\delta_{k}(h)\right)+C\left(\frac{3 h}{2 a}-\frac{h^{3}}{2 a^{3}}\right) & 0 \leq h \leq a \\ C_{0}+C & h>a,\end{cases}$

in which the Kronecker delta function $\delta_{k}(h)$ is 1 for $h=0$ and 0 for $h \geq 0$. The nugget variance $\left(C_{0}\right)$ is 0.172 , the partial sill $(C)$ is 1.270 and the range $(a)$ is $10 \mathrm{~km}$.

We used two different kriging techniques for the prediction of rainfall fields. Ordinary kriging was used to interpolate the measurements of the raingauges of the experimental network. To combine both the raingauges and the radar, we used ordinary colocated cokriging (Goovaerts, 1997). In the latter, radar is used as secondary data and influences the kriging prediction directly. Colocated cokriging accounts for the global linear correlation between raingauges and radar. For more details on the spatial prediction methods we refer to Schuurmans et al. (2007).

\subsection{Rainfall scenarios}

The following scenarios of daily rainfall were used as input for the hydrological model to study its sensitivity:

(1) uni_cabauw; spatially uniform rainfall fields using only the raingauge station Cabauw from the automatic KNMI network. This station is located within the Lopikerwaard catchment and would therefore be a logical choice for hydrological studies if no other data were available.

(2) uni_bilt; spatially uniform rainfall fields using only the raingauge station De Bilt from the automatic KNMI network. Station De Bilt is a well known raingauge station in the Netherlands (close to KNMI headquarters) and is often used in hydrological studies without any consideration. This is mainly due to the fact that this data is easily available, free and central in the Netherlands, which in general gives the impression that it is a representative station.

(3) var_okraing; spatially variable rainfall field, using ordinary kriging to make point predictions using all the raingauges of the experimental network.

(4) uni_okraing; same as scenario (3), but spatially uniform. Each day, the areal average of the daily spatially variable rainfall field is calculated, providing a spatially uniform rainfall field.

(5) var_radar; spatially variable rainfall field, using the operational available radar data of KNMI.

(6) uni_radar; same as scenario (5), but spatially uniform. 


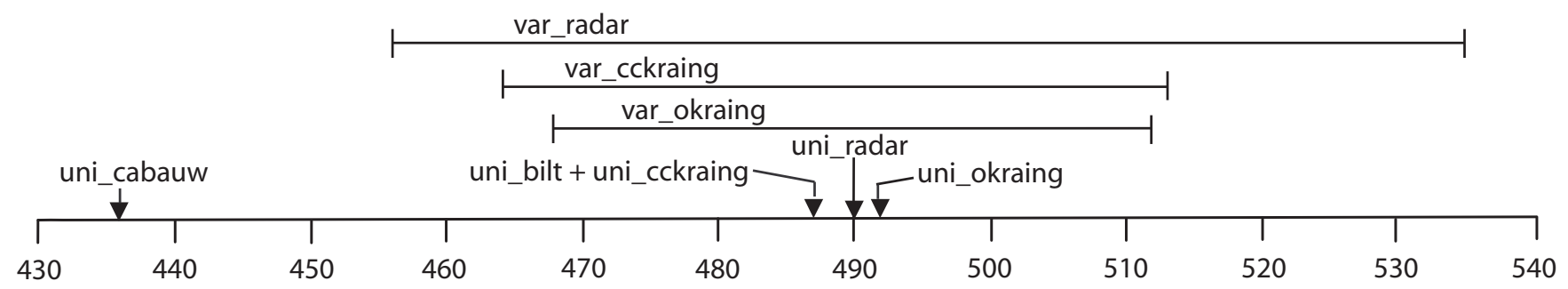

Fig. 3. Spatial variation (range of values) of accumulated rainfall (March to October 2004) for all 8 scenarios. Spatially uniform scenarios only have one value.
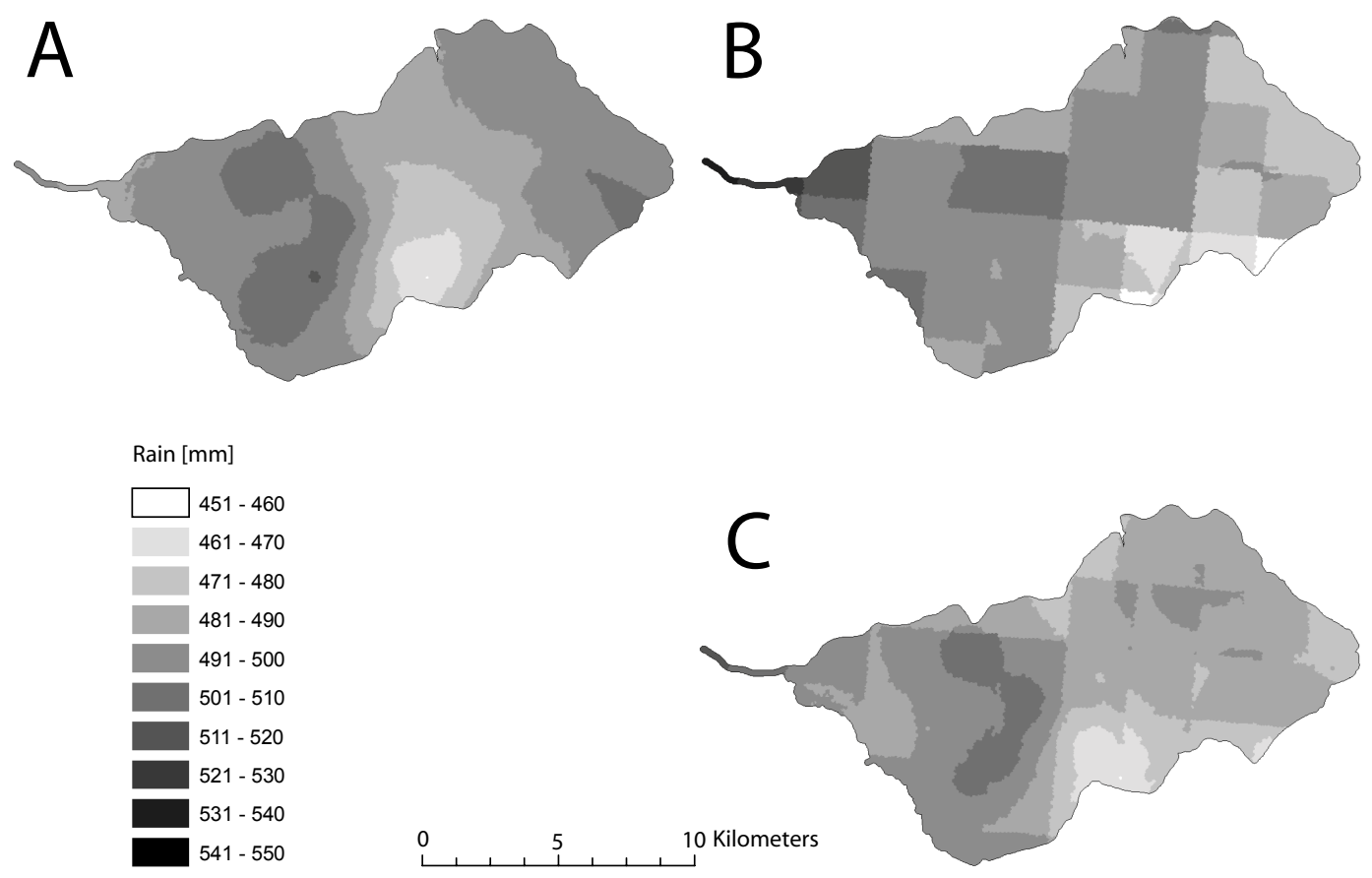

Fig. 4. Spatial distribution of total rainfall from March to October 2004 as derived by (A) ordinary kriging (mean value $492 \mathrm{~mm}$ ), (B) operational available radar (mean value $490 \mathrm{~mm}$ ) and (C) ordinary colocated cokriging (mean value $487 \mathrm{~mm}$ ).

(7) var_cckraing; spatially variable rainfall field, using ordinary colocated cokriging to make point predictions using all the raingauge stations of the experimental network as well as the operational KNMI radar data.

(8) uni_cckraing; same as scenario (7), but spatially uniform.

For the time series running from March to October 2004 there were 22 days (10\%) with missing or incomplete radar images. No radar image means no scenario 5 until 8 for these days. In that case we used scenario 3 or 4 (ordinary kriging).

Figure 3 shows the total rainfall amount for the period March to October 2004 for all 8 scenarios, that was calculated by summing up the daily rainfall input of each model node. In Fig. 3 the spatially variable scenarios therefore show a range of values whereas the spatially uniform scenarios only have a single value. The total rainfall amount of station Cabauw stands out as it is about $10 \%$ less than the other uniform rainfall fields. Nevertheless, this raingauge station is the only raingauge station of the automatic KNMI network located within the Lopikerwaard catchment and would have been a logical choice for hydrological studies.

Figure 4 shows the spatial distribution of the total rainfall from March to October 2004 as derived by ordinary kriging (scenario 3), operational available radar (scenario 5) and ordinary colocated cokriging (scenario 7). We see that even over a relatively large period of 7 months, there are differences in rainfall of 50 to $100 \mathrm{~mm}$ over distances of about $15 \mathrm{~km}$. The operational radar data show most spatial variability, followed by the rainfall fields obtained by ordinary 


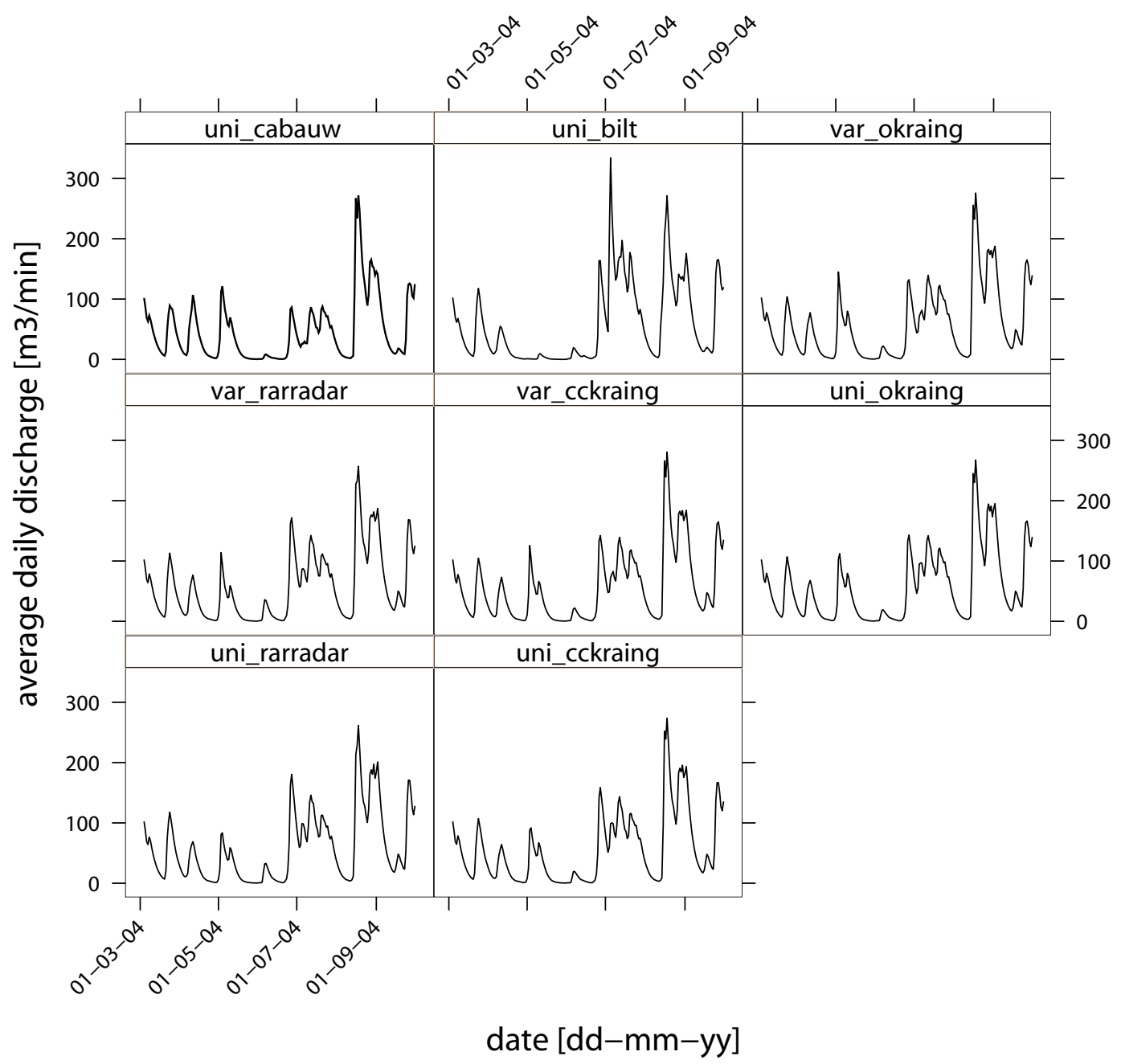

Fig. 5. Hydrographs of pumping station Koekoek for all the rainfall scenarios.

colocated cokriging and ordinary kriging, as could also be seen in Fig. 3. We also see in Fig. 4 that for the three spatially variable rainfall scenarios, the smallest amount of total rainfall fell in the mid-south and the largest amount of rainfall fell in the west of the Lopikerwaard catchment.

\section{Results}

\subsection{Discharge}

With the hydrological model, we calculated for each rainfall scenario the average daily discharge of all the main pumping stations in the Lopikerwaard (Fig. 1d) for the period March to October 2004. We select two pumping stations, the one belonging to the largest subcatchment (Koekoek) and the one belonging to the smallest subcatchment (Hoekse Molen), to show the hydrographs that result from the different rainfall scenarios. Figures 5 and 6 show the hydrographs for all rain- fall scenarios of respectively pumping station Koekoek and Hoekse Molen. The hydrographs clearly show that for both pumping stations the rainfall scenario uni_bilt deviates most from the other scenarios. This holds true for all 4 pumping stations. Two major differences in the hydrographs are caused by a rainfall event in the beginning of May that was registered in the Lopikerwaard but not in De Bilt and a rainfall event in the beginning of July that was registered in De Bilt but was less prominent in the Lopikerwaard.

For all 4 pumping stations we analyzed the hydrographs and calculated the mean and standard deviation of the average daily discharge. The results are given in Fig. 7. Most prominent are the results from the two rainfall scenarios that used only a single raingauge, uni_cabauw and uni_bilt. Using only rainfall data from station Cabauw leads for all pumping stations to lower discharges and lower variation in discharge. Using only rainfall data from station De Bilt gives about the same mean, but yields a higher variation in discharge for all 


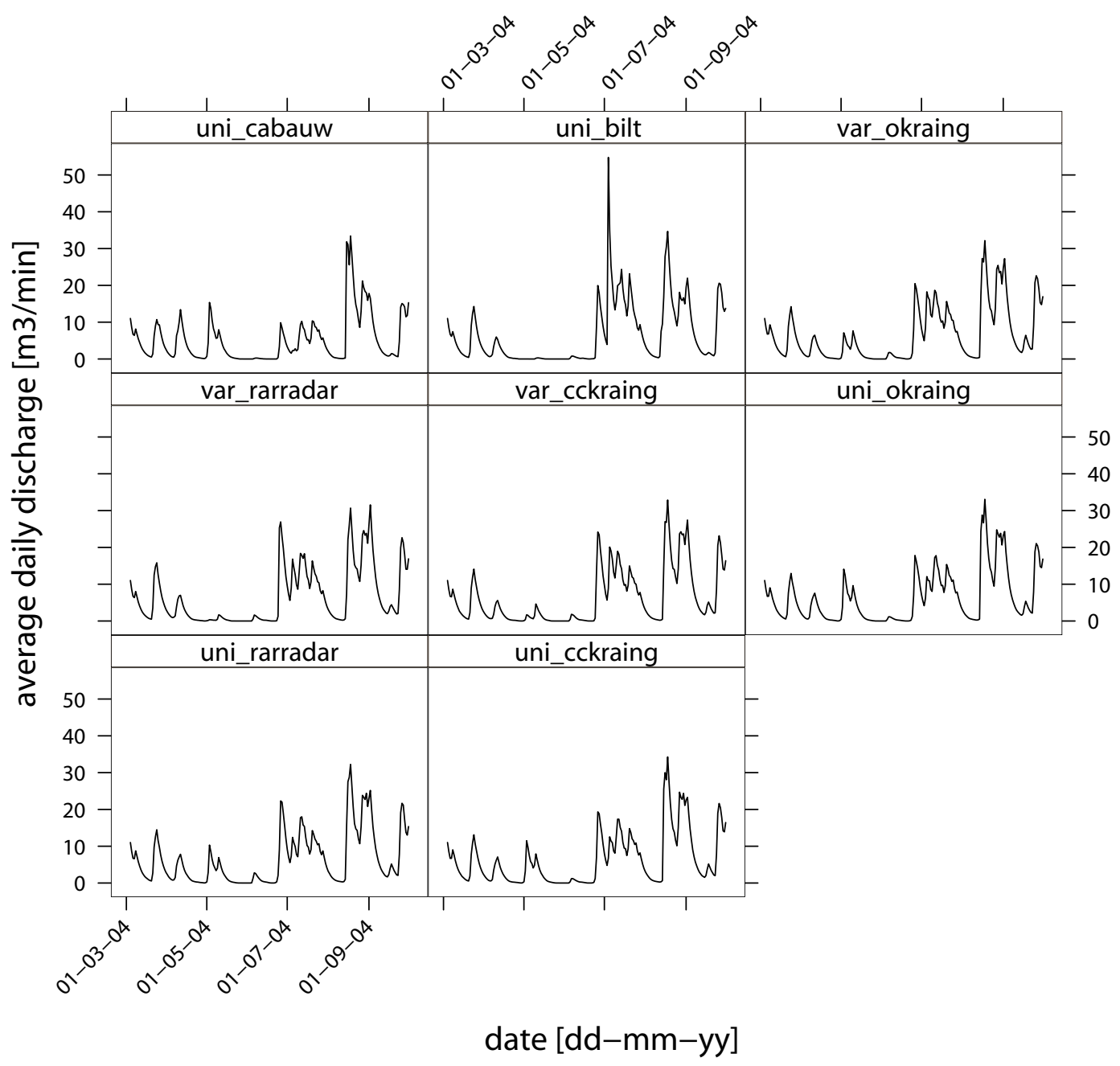

Fig. 6. Hydrographs of pumping station Hoekse Molen for all the rainfall scenarios.

Table 1. Percentage of days within March-October 2004 the discharge threshold value is exceeded. Threshold values vary per pumping station and are given underneath their names.

\begin{tabular}{lllll}
\hline Scenario & $\begin{array}{l}\text { Hoekse Molen } \\
15 \mathrm{~m}^{3} / \mathrm{min}\end{array}$ & $\begin{array}{l}\text { De Pleyt } \\
65 \mathrm{~m}^{3} / \mathrm{min}\end{array}$ & $\begin{array}{l}\text { Keulevaart } \\
65 \mathrm{~m}^{3} / \mathrm{min}\end{array}$ & $\begin{array}{l}\text { De Koekoek } \\
115 \mathrm{~m}^{3} / \mathrm{min}\end{array}$ \\
\hline uni_cabauw & 8 & 9 & 7 & 10 \\
uni_bilt & 17 & 19 & 17 & 22 \\
var_okraing & 15 & 17 & 11 & 17 \\
uni_okraing & 13 & 15 & 10 & 16 \\
var_rarradar & 16 & 17 & 12 & 15 \\
uni_rarradar & 14 & 16 & 11 & 16 \\
var_cckraing & 15 & 17 & 11 & 17 \\
uni_cckraing & 12 & 14 & 11 & 16 \\
\hline
\end{tabular}

pumping stations. Between the spatially variable and spatially uniform rainfall scenarios we see little difference in the discharge statistics.
We also looked at the occurrence of high discharge. For each pumping station we defined a threshold value for the discharge, that more or less equals the sum of the mean and 
standard deviation of the discharge. Table 1 shows the percentage of days within the period March-October 2004 (212 days) that discharge threshold values were exceeded, with the threshold values given underneath the pumping stations. From this table we see again that for all subcatchments the rainfall scenario based on only data from station Cabauw (uni_cabauw) leads to a lower amount of discharge peaks, while using data from only station De Bilt leads to a higher amount of discharge peaks in comparison to the other rainfall scenarios.

Although we cannot find structural differences in the time series statistics of discharge between spatially variable and spatially uniformed rainfall scenarios, there are certainly differences in discharge on specific days. These differences are caused by the spatial distribution of rainfall.

\subsection{Groundwater}

For one randomly selected node, number 15552 located in the northwest, we show the development of groundwater level in time for all rainfall scenarios (Fig. 8). As we saw in the hydrographs, the development of groundwater level in time using rainfall scenario uni_bilt differs most from the other rainfall scenarios. Again, the main differences are found around May and July. Using data only from station De Bilt results in lower groundwater levels in May and higher groundwater levels in July in comparison to the other scenarios.

We analyzed the development of groundwater level in time for all nodes. Figure 9 shows the spatial distribution of the mean temporal groundwater level and Fig. 10 shows the spatial distribution of the standard deviation of the temporal groundwater level. Note that the maps clearly show the inprint of the drainage network as a result of the artificially maintained water levels. To show the small differences between the spatially uniform and spatially variable scenarios, the spatial distribution of the difference (variable minus uniform scenarios) is shown as well. For all scenarios the spatial pattern of mean temporal groundwater level is more or less the same, although uni_cabauw and uni_bilt both show slightly lower groundwater levels in the eastern part of the Lopikerwaard. Using spatially variable instead of spatially uniform rainfall scenarios leads to slightly $(2 \mathrm{~cm})$ higher mean groundwater levels in the west and east and slightly $(2 \mathrm{~cm})$ lower groundwater levels in the middle part of the Lopikerwaard if we use information from the raingauges. Using information from the radar leads to slightly $(2 \mathrm{~cm})$ lower groundwater levels in the west and slightly higher (2$4 \mathrm{~cm}$ ) groundwater levels in the eastern part of the Lopikerwaard. The spatial pattern of the standard deviation of the temporal groundwater level of uni_bilt differs most from the other scenarios, showing an overestimation of the temporal variation of groundwater level. Uni_cabauw leads to slightly lower standard deviations. Using spatially distributed rainfall scenarios instead of spatially uniform scenarios leads to

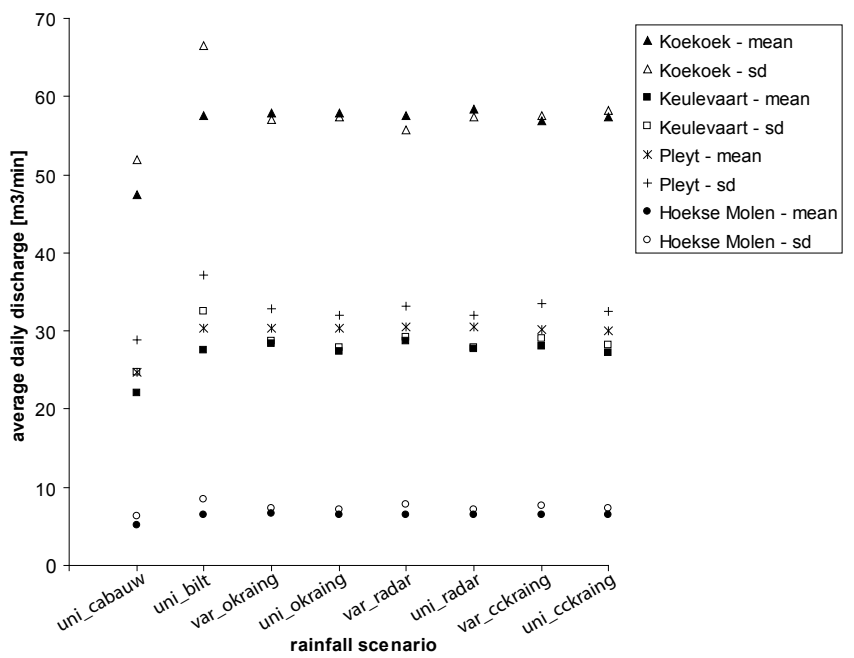

Fig. 7. Mean and standard deviation of the average daily discharge for all 4 pumping stations in the Lopikerwaard for the period March-October 2004.

higher standard deviations in the north and lower standard deviation in the south.

To get an impression of the effect of the different rainfall scenarios on day-to-day spatial variability, we selected one day with highly spatially variable rainfall. Figure 11 shows the rainfall within the Lopikerwaard for all rainfall scenarios at 1 May 2004. Figure 12 shows its effect on the groundwater level (m from ground level) throughout the Lopikerwaard for all the rainfall scenarios. Again, rainfall scenario uni_bilt differs most from the other rainfall scenarios. At 1 May 2004 we see that the groundwater level within the Lopikerwaard using rainfall scenario uni_bilt is much lower than if we use rainfall information from the catchment itself, even if we use only one raingauge (uni_cabauw). The spatially variable rainfall scenarios all show a different spatial pattern of groundwater level than the corresponding spatially uniform rainfall scenarios. Using spatially variable rainfall scenarios leads at 1 May 2004 to deeper groundwater levels in the north-eastern part of the Lopikerwaard.

\subsection{Soil moisture}

Again, we use node number 15552 to show the development of the soil moisture content in time for all scenarios (Fig. 13). Similar to the hydrographs and groundwater the development of soil moisture content in time using scenario uni_bilt differs most from the other scenarios. Again, the main differences occur around May and July. Using data only from station De Bilt results in lower soil moisture contents in May and higher soil moisture contents in the beginning of July in comparison to the other rainfall scenarios. The spatially variable rainfall scenarios yield at specific days higher peaks than the corresponding spatially uniform rainfall scenarios. 


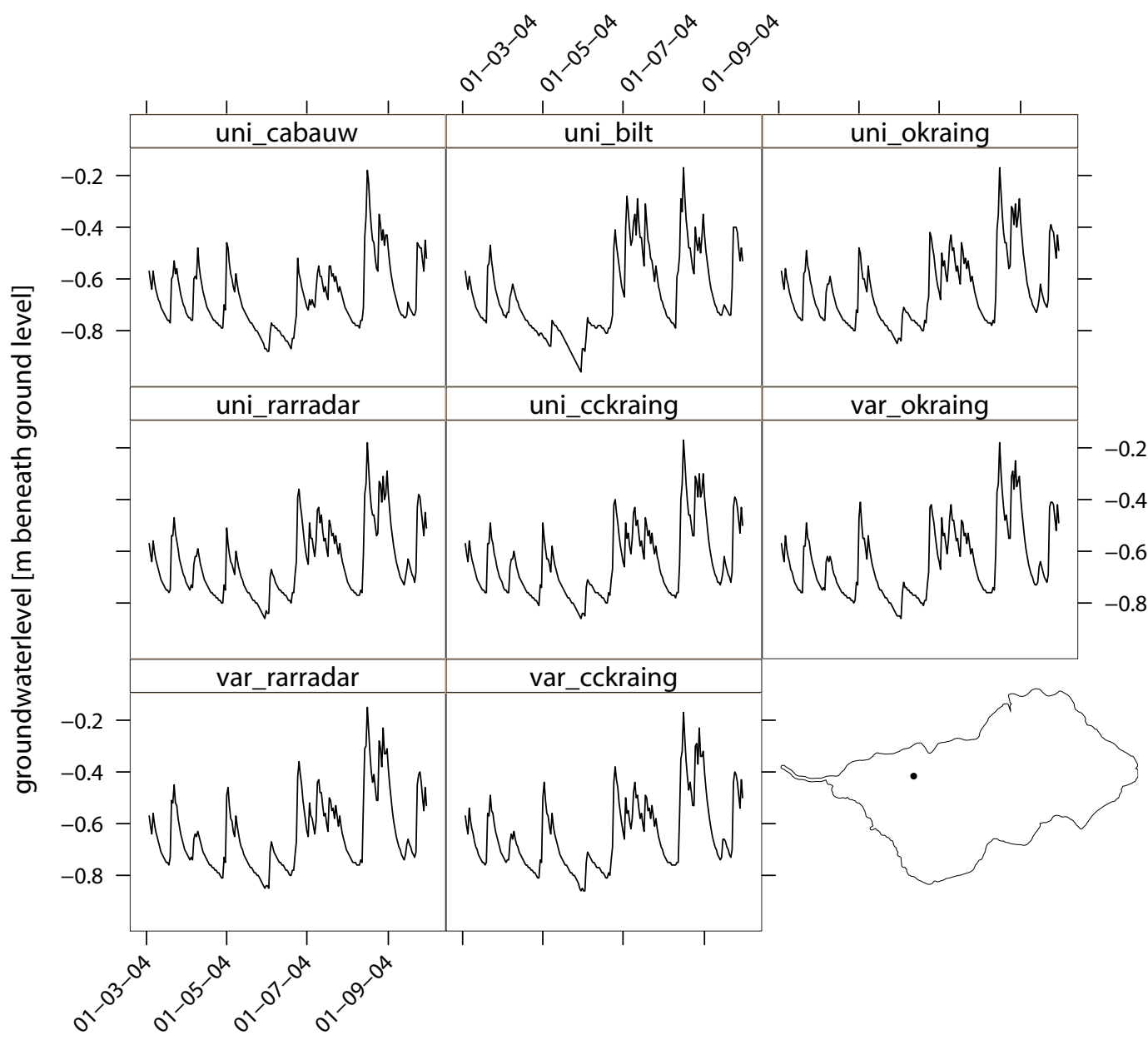

date $[\mathrm{dd}-\mathrm{mm}-\mathrm{yy}]$

Fig. 8. Development of groundwater level [m from ground level] in time of node number 15552 for all rainfall scenarios. The location of node number 15552 is given in lower right corner.

Also for soil moisture we analyzed its development in time for all nodes. The results are similar to that of groundwater and not shown here. The spatial pattern of the mean temporal soil moisture content is for all the rainfall scenarios more or less the same. The temporal variance in soil moisture content is overestimated when using rainfall information from station De Bilt in comparison to the other rainfall scenarios. For the other scenarios, the spatial pattern of temporal variation of soil moisture content is more or less the same.

To get insight in the day-to-day variability of soil moisture, Fig. 14 shows the effect of the 1 May rainfall event (Fig. 11) on the soil moisture content within the Lopikerwaard. The soil within the Lopikerwaard using rainfall scenario uni_bilt is much drier than if we use rainfall information from the catchment itself, even if we use only one raingauge (uni_cabauw). The spatially variable rainfall scenarios all show a different spatial pattern of soil moisture than the corresponding spatially uniform rainfall scenarios. Using spatially variable rainfall scenarios leads at 1 May 2004 to higher soil moisture content in the western part and lower soil moisture content in the north-eastern part of the Lopikerwaard. This corresponds with the spatial pattern of rainfall (Fig. 11). For all scenarios, the lowest soil moisture contents correspond with the urban areas of the Lopikerwaard (Fig. 1b).

\section{Conclusions and discussion}

In this study we show that at specific days the spatial variability of daily rainfall has a major effect on discharge and spatial distribution of groundwater level and soil moisture content of the catchment. However, for the general behaviour of the hydrological system the use of uniform areal average rainfall suffices. Above all, this study shows that there is a 

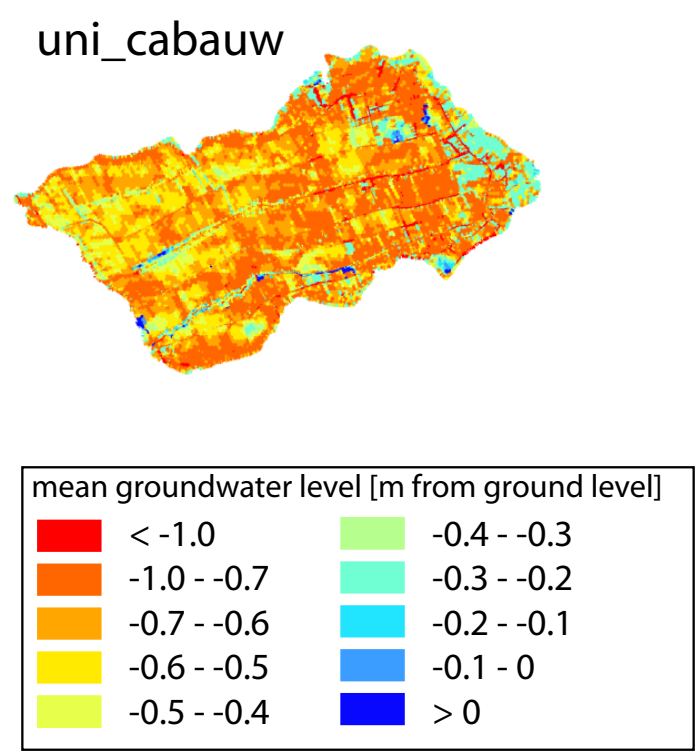

uni_okraing

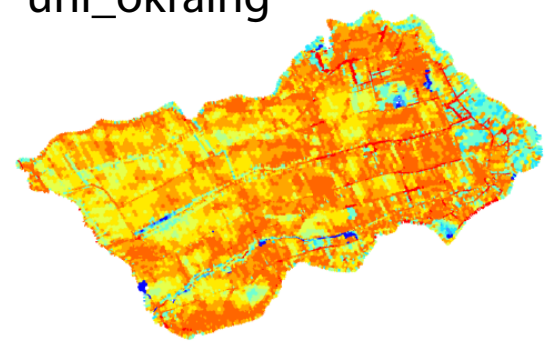

uni_radar

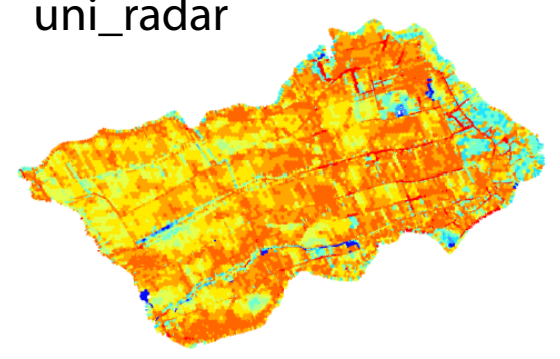

uni_cckraing

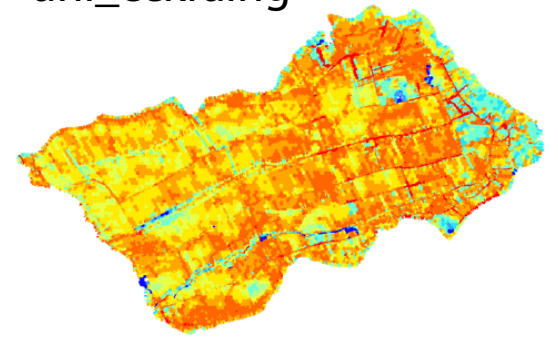

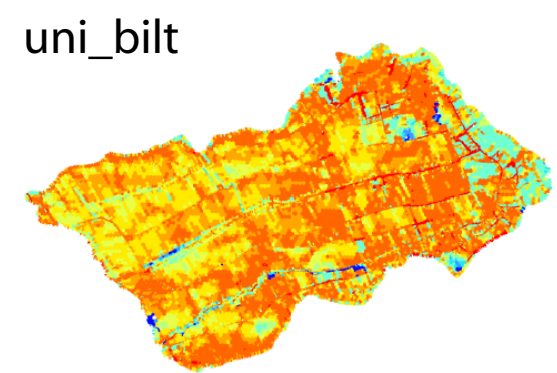
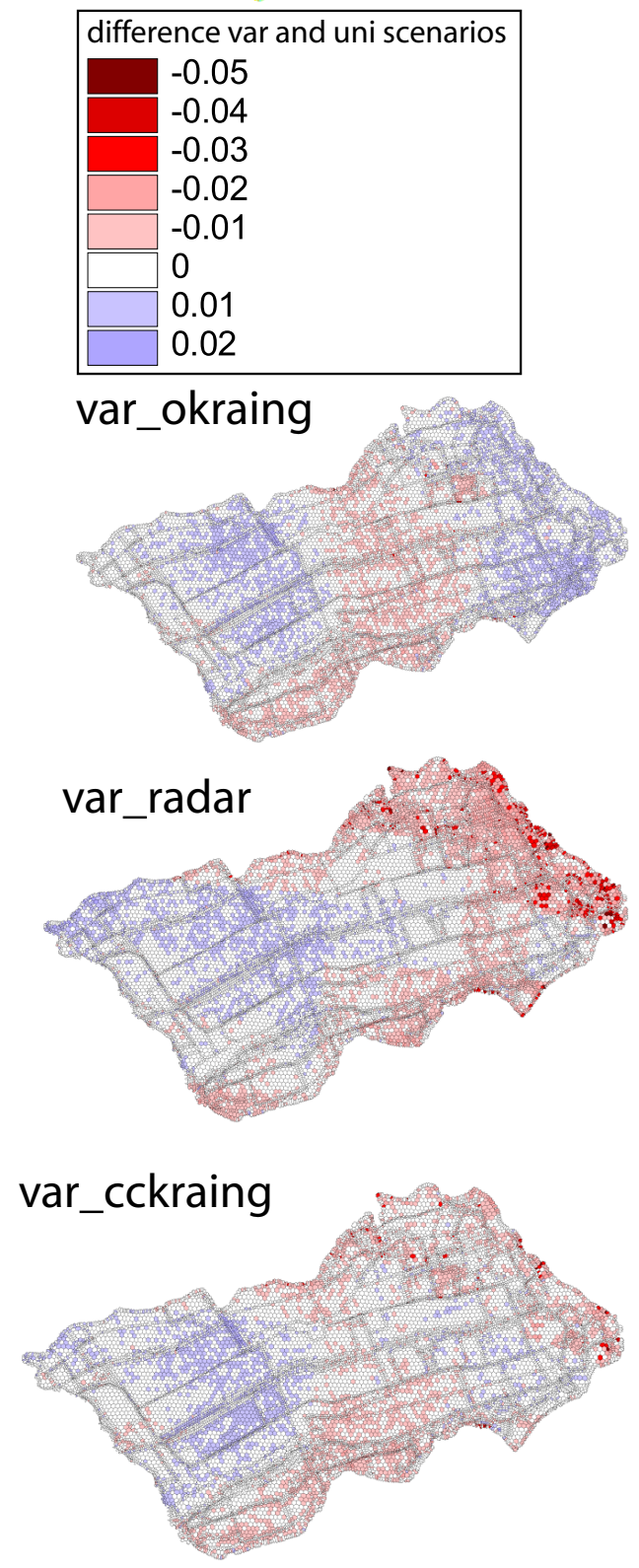

Fig. 9. Spatial pattern of mean groundwater level [m from ground level] during March-October 2004 for all rainfall scenarios. For the spatially variable scenarios the spatial pattern of the differences (variable minus uniform) to the corresponding spatially uniform scenarios are shown. 


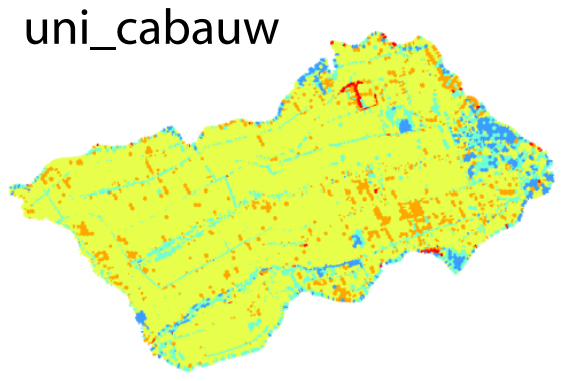

\begin{tabular}{|c|}
\hline standard deviation groundwater level $[\mathrm{m}]$ \\
$0.00-0.05$ \\
$0.05-0.10$ \\
$0.10-0.15$ \\
$0.15-0.20$ \\
$>0.20$ \\
\hline
\end{tabular}

\section{uni_okraing}
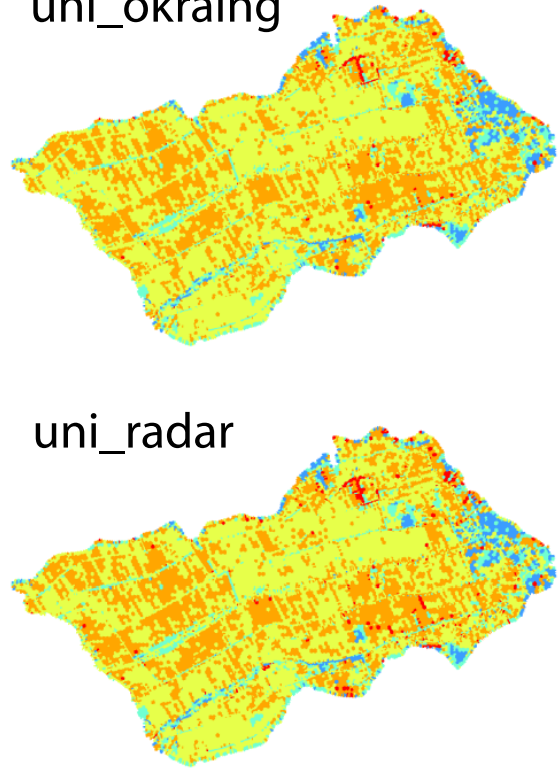

uni_cckraing

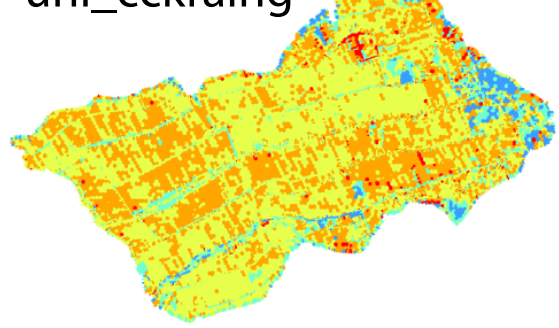

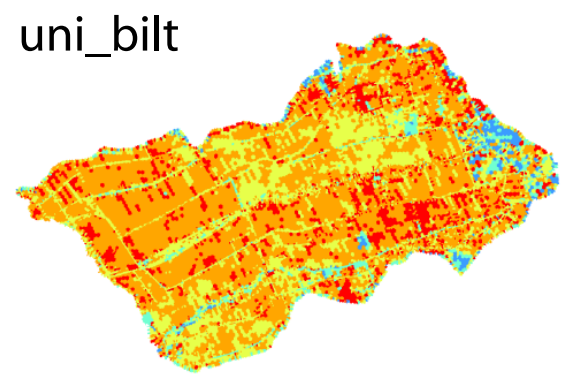

difference var and uni scenarios

\begin{tabular}{|l|l|}
\hline & -0.03 \\
\hline \hline & -0.02 \\
\hline \hline & -0.01 \\
0 \\
\hline \hline & 0.01 \\
0.02 \\
0.03 \\
\hline \hline \\
0.04 \\
\hline
\end{tabular}

var_okraing

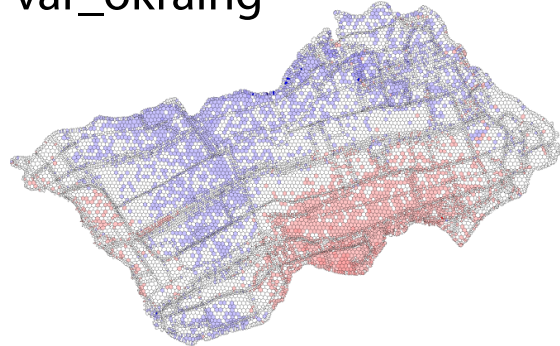

var_radar
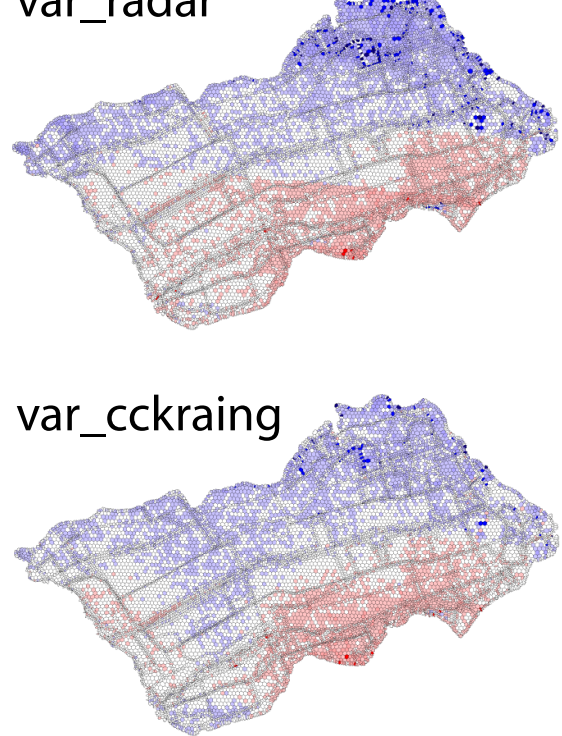

Fig. 10. Spatial pattern of temporal standard deviation of groundwater level [m] during March-October 2004 for all rainfall scenarios. For the spatially variable scenarios the spatial pattern of the differences (variable minus uniform) to the corresponding spatially uniform scenarios are shown. 

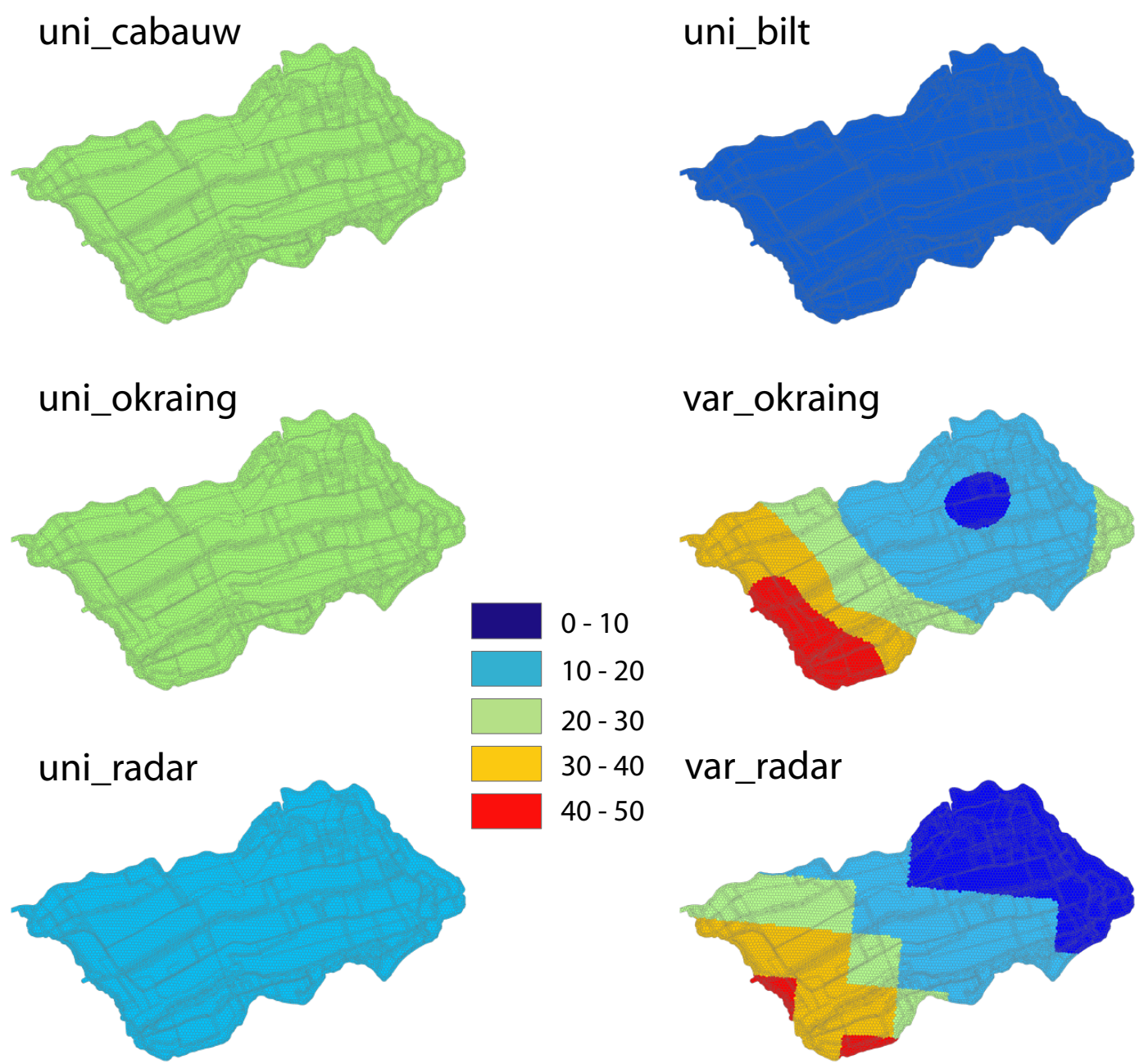

$20-30$

30 - 40 var_radar

$40-50$
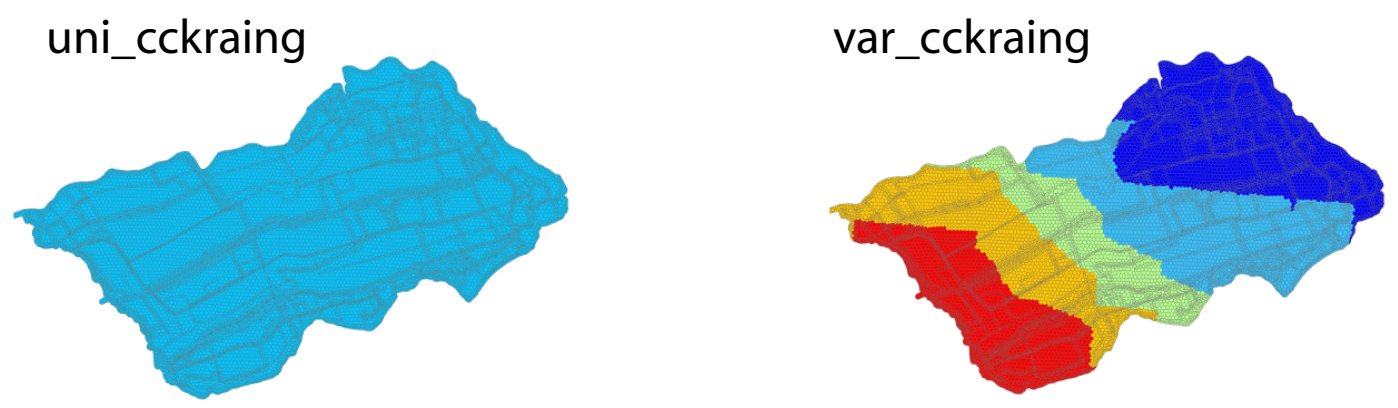

Fig. 11. Spatial pattern of rainfall in mm on 1 May 2004 for the different rainfall scenarios in the Lopikerwaard.

great risk in using a single raingauge, especially when located outside the catchment, for the prediction of discharge, spatial distribution of soil moisture and spatial distribution of groundwater level. For the general hydrological behaviour, this study corroborates the conclusion stated by Obled et al. (1994) that the spatial distribution of rainfall must be taken into account more because it improves the basin-average in- coming volume rather than because of some dynamic interactions with flow-generating processes. However, for particular days, incorporating spatially variable information on rainfall is of great importance for the spatial distribution of interior catchment response.

Operational radar products proved to be a good method to capture the spatial variability of daily rainfall. The total 

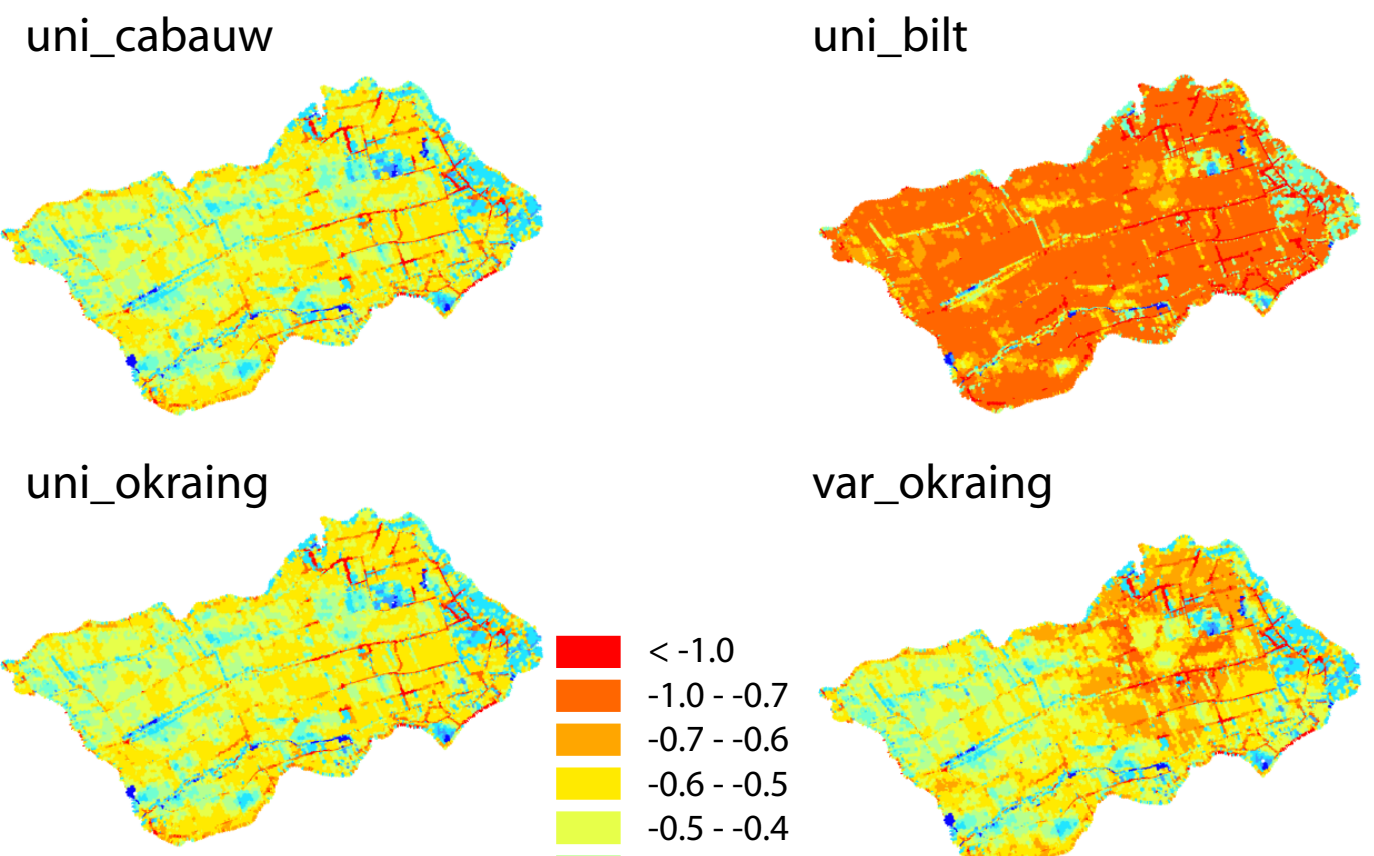

var_okraing

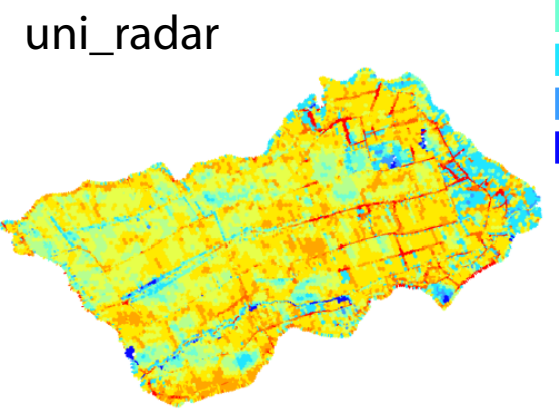

$-0.4--0.3$

$-0.3--0.2$

$-0.2--0.1$
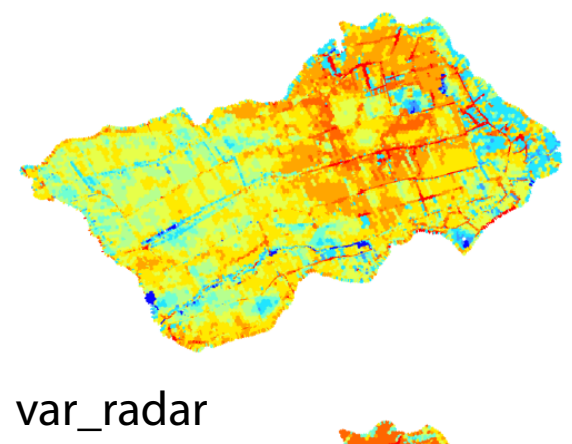

$-0.1-0$

$>0$
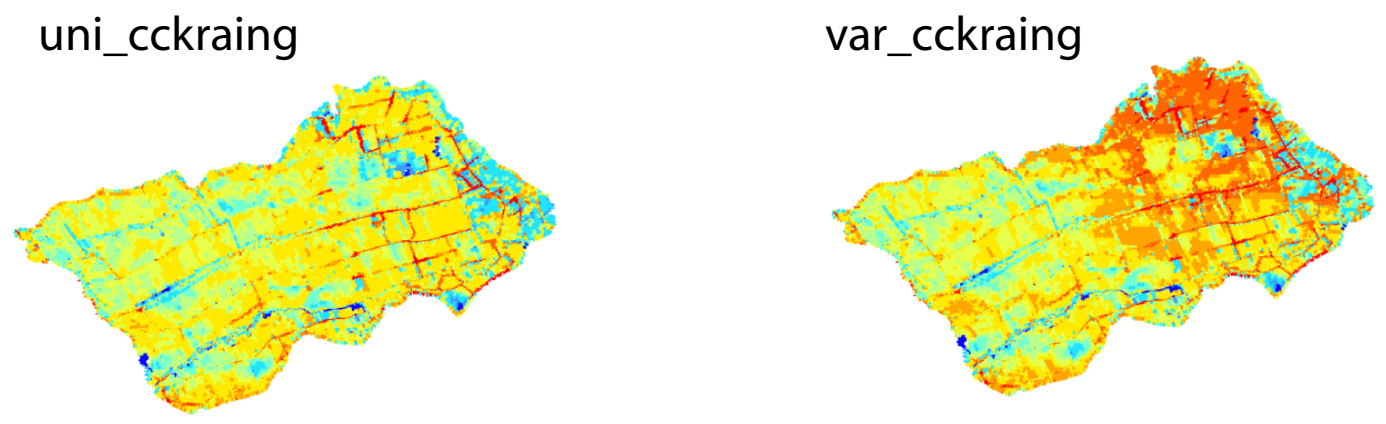

Fig. 12. Spatial variation of groundwater level [m from ground level] on 1 May 2004 for the different rainfall scenarios.

amount of rainfall for the period March-October 2004 as estimated by the operational radar corresponds to the total amount found by the kriged rainfall fields based on 30 raingauges within the catchment. The spatial variation (range of values) of the total rainfall was found to be higher for radar than for the kriged raingauges. This is, among other factors influencing radar-estimated rainfall accuracy, maybe also caused by the fact that the dense network of raingauges was not equally distributed over the catchment. However, based on the results of spatial prediction of soil moisture content and groundwater level at 1 May 2004 (Figs. 14 and 12) we can conclude that the same pattern is produced using either one of the spatially distributed rainfall scenarios. Also considering the hydrographs and the discharge statistics, we 


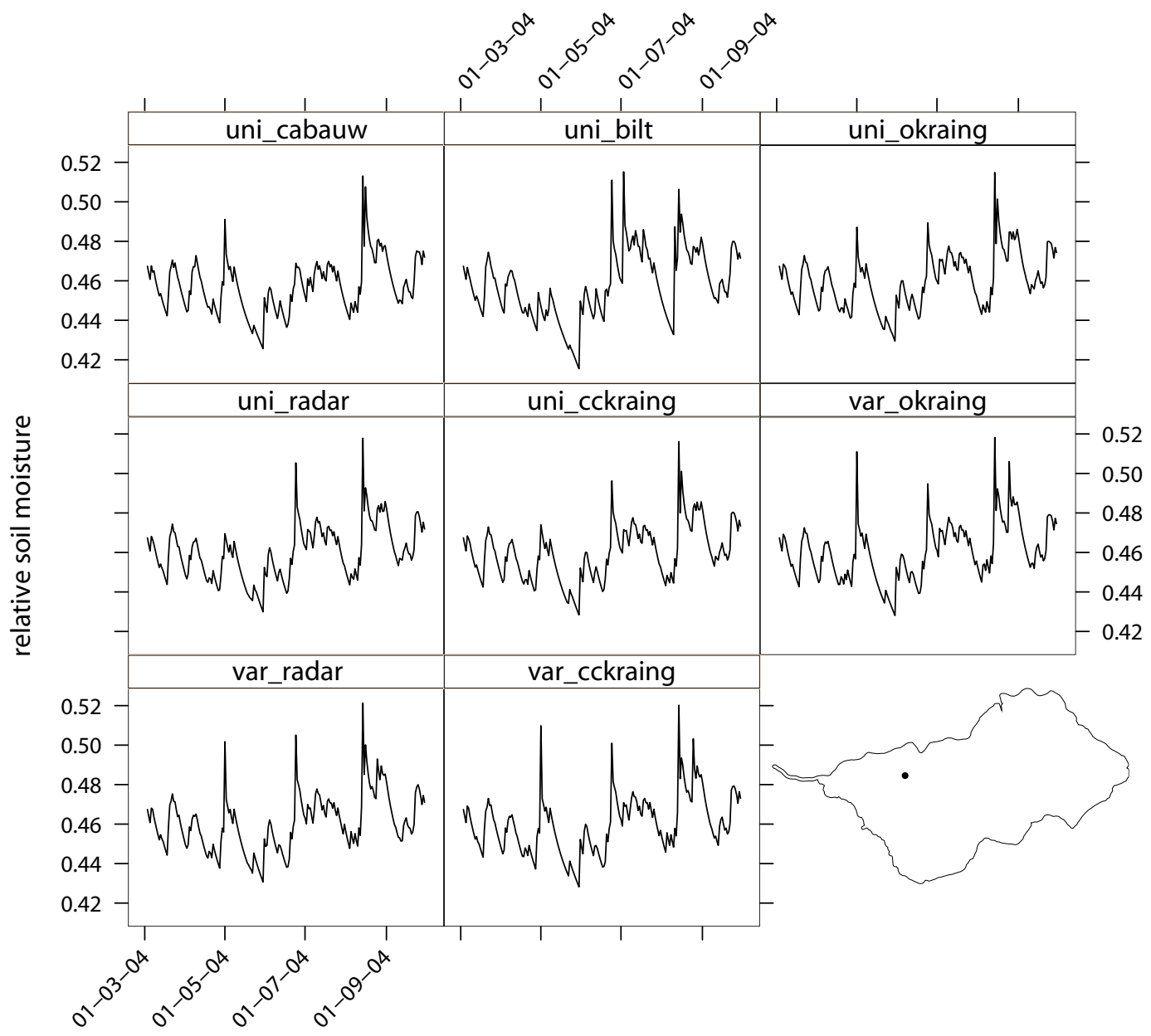

date [dd-mm-yy]

Fig. 13. Development of soil moisture content in time of node number 15552 for all rainfall scenarios. The location of node 15552 is given in lower right corner.

can conclude that using radar-estimated rainfall input leads to similar (or slightly more varying) discharges as using a dense network of raingauges. This shows that standard rangecorrected radar products are sufficiently informative about the spatial variability of rainfall to be used in hydrological applications.

This study uses a hydrological model to study the sensitivity of spatially variable rainfall on interior catchment response. This can of course only be done if the model reflects the true catchment response. As often mentioned for this kind of studies, the results are dependent on the spatiotemporal variation of rainfall and the characteristics of the catchment, or in this case the characteristics of the hydrological model. It is known that there is a space-time correlation in rainfall variability. Krajewski et al. (1991) found that basin response shows higher sensitivity with respect to the temporal resolution than to spatial resolution of the rainfall data.
This study shows that even for daily rainfall it is important to take account of the spatial rainfall variability, if one aims to predict the internal hydrological state of the catchment.

The spatial variability of rainfall as well as the sensitivity of the hydrological model to this spatial variability is often neglected in hydrological studies. Failing to consider spatial variability of rainfall adequately will lead to errors in the values of the model parameters (e.g. storage capacity, drainage resistance) which will be wrongly adjusted to compensate for errors in the rainfall input data. Wrong conclusions about the hydrological reaction of a specific area due to e.g. climate change can be one of the consequences. This study clearly shows the danger of using rainfall information from a single raingauge, which is still common practice in hydrological engineering, because of cost considerations or because of reluctance of using operational radar data (e.g. because its prediction quality is often discussed). With this study we show 

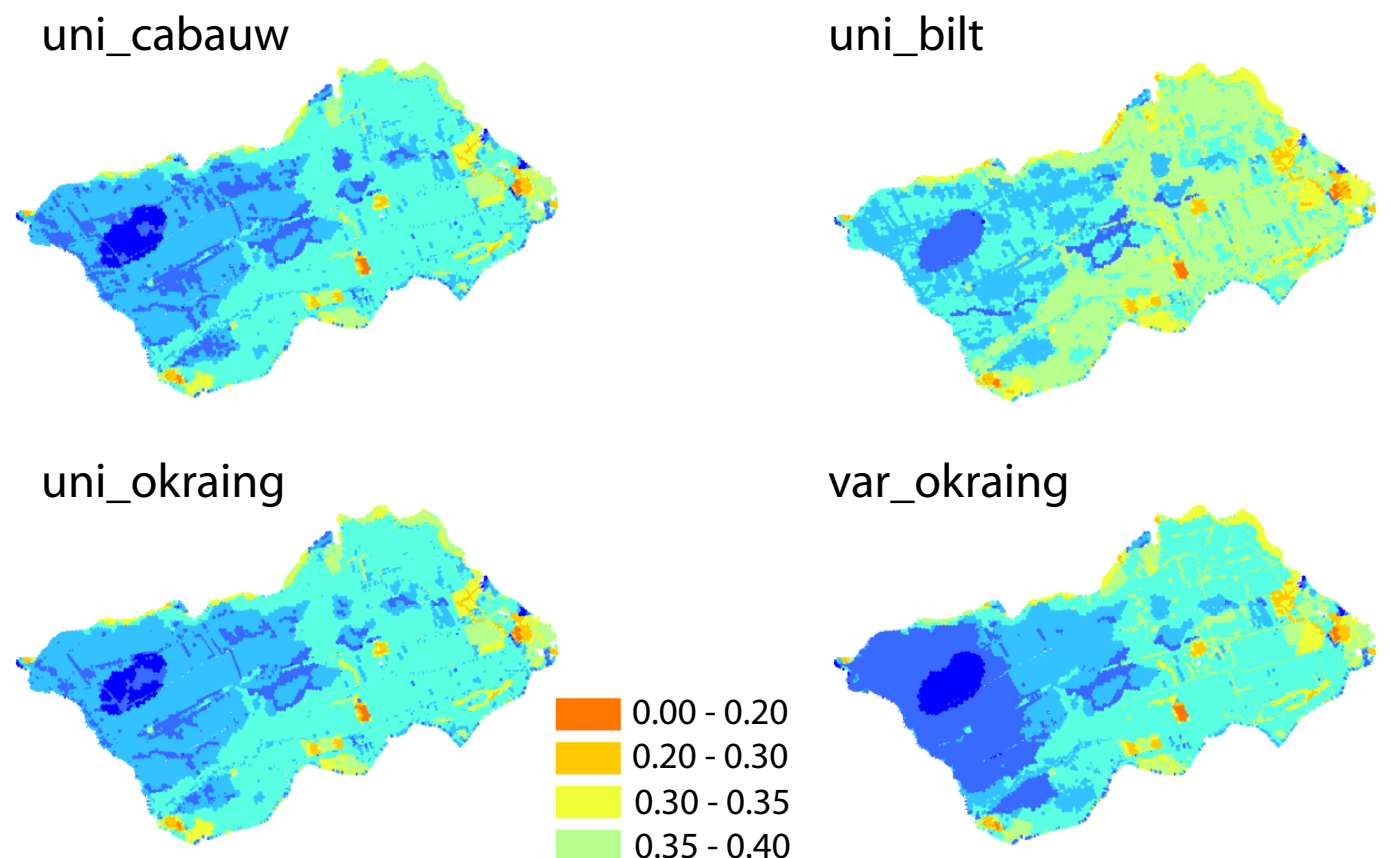

var_okraing

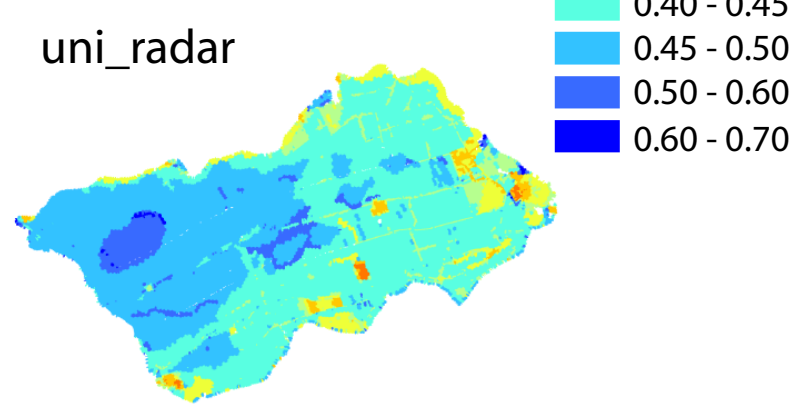

$0.00-0.20$

$0.20-0.30$

$0.30-0.35$

$0.35-0.40$

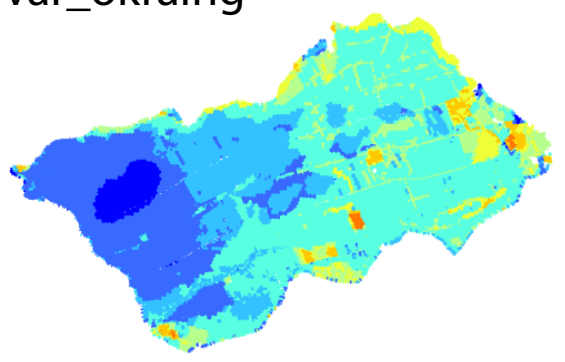

$0.40-0.45$
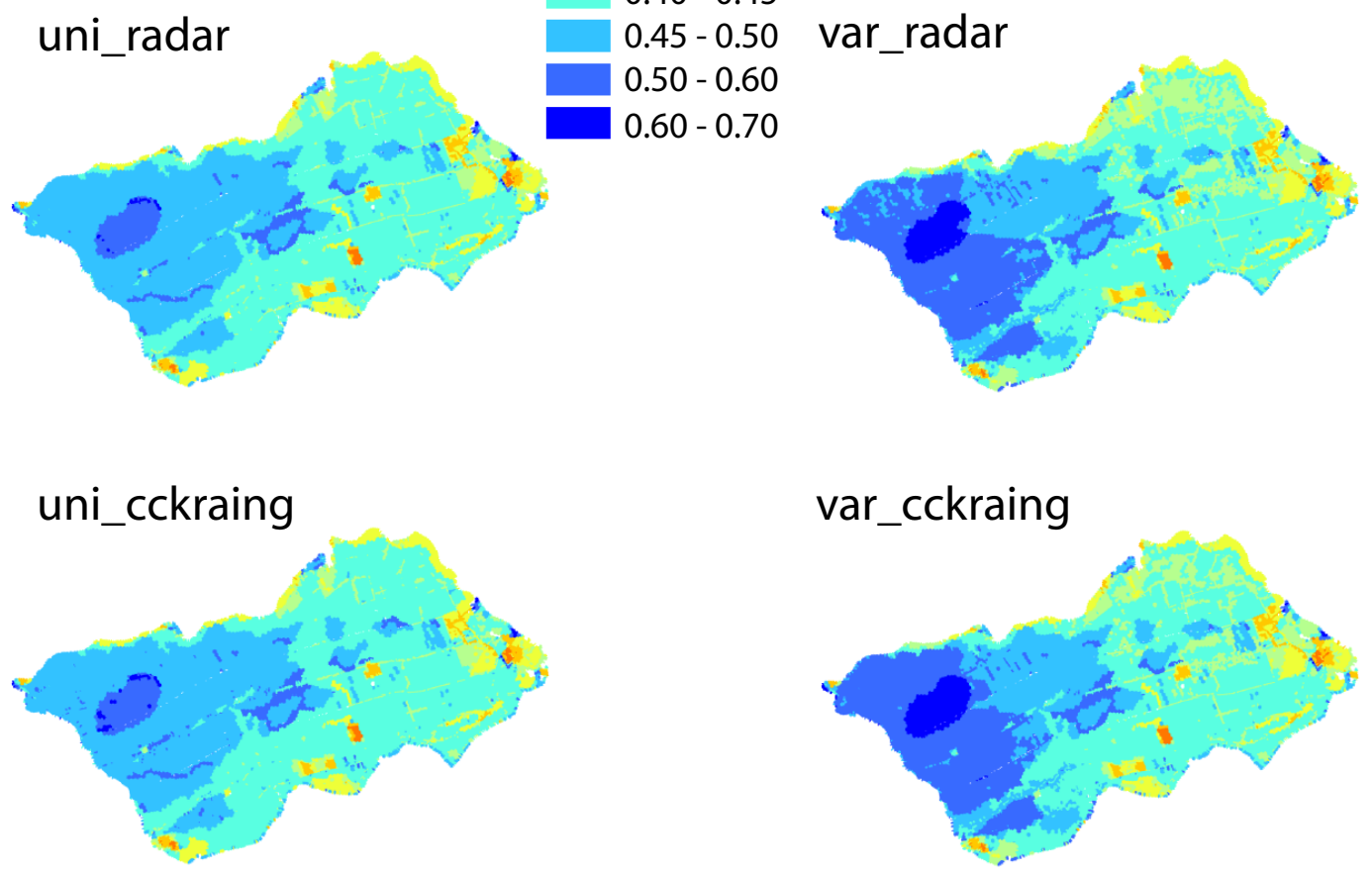

Fig. 14. Spatial pattern of soil moisture content [-] on 1 May 2004 for the different rainfall scenarios in the Lopikerwaard.

the potential and necessity of using the operational available radar products in hydrological studies.

Acknowledgements. J. M. Schuurmans was financially supported by TNO.

Edited by: J. D. Kalma

\section{References}

Arnaud, P., Bouvier, C., Cisner, L., and Dominguez, R.: Influence of rainfall spatial variability on flood prediction, J. Hydrol., 260, 216-230, 2002.

Battan, L. J.: Radar Observations of the Atmosphere, University of Chicago Press, Chicago, 1973.

Bell, V. A. and Moore, R. J.: The sensitivity of catchment runoff 
models to rainfall data at different spatial scales, Hydrol. Earth Syst. Sci., 4, 653-667, 2000,

http://www.hydrol-earth-syst-sci.net/4/653/2000/.

Carpenter, T. M., Georgakakos, K. P., and Sperfslagea, J. A.: On the parametric and NEXRAD-radar sensitivities of a distributed hydrological model suitable for operational use, J. Hydrol., 253, 169-193, 2001.

Cressie, N. A. C.: Statistics for spatial data, Revised Edition, John Wiley \& Sons, Inc., New York, 1993.

De Bruin, H. A. R.: From Penman to Makkink, in: Proc. and Inf. Vol. 39, TNO Committee on Hydrological Research, pp. 5-31, 1987.

Gekat, F., Meischner, P., Friedrich, K., Hagen, M., Koistinen, J., Michelson, D. B., and Huuskonen, A.: Weather Radar, Principles and Advanced Applications. Springer, Berlin, Germany, Ch. The State of Weather Radar Operations, Networks and Products, 2004.

Goodrich, D. C., Faures, J. M., Woolhiser, D. A., Lane, L. J., and Sorooshian, S.: Measurements and analysis of small-scale convective storm rainfall variability, J. Hydrol., 173, 283-308, 1995.

Goovaerts, P.: Geostatistics for Natural Resources Evaluation, Oxford University Press, New York, 1997.

Holleman, E. T., Zaadnoordijk, W. J., Meuter, N. H., Roelandse, A. S., and Veldhuizen, A.: Wateropgave HDSR-West (in Dutch), Tech. Rep. Reference: 9M8931/R00002/HTD/Rott1, Royal Haskoning, 2005.

Holleman, I.: VPR adjustment using a dual CAPPI technique, in: Proc. of ERAD, Vol. 2, Copernicus GmbH, pp. 25-30, 2004.

Isaaks, E. H. and Srivastava, R. M.: Applied Geostatistics, Oxford University Press, New York, 1989.

Krajewski, W. F., Lakshmi, V., Georgakakos, K., and Jain, S.: A monte carlo study of rainfall sampling effect on a distributed catchment model, Water Resour. Res., 27(1), 119-128, 1991.
Krajewski, W. F. and Smith, J. A.: Radar hydrology: rainfall estimation, Adv. Water Resour., 25(8-12), 1387-1394, 2002.

Obled, C., Wending, J., and Beven, K.: The sensitivity of hydrological models to spatial rainfall patterns: an evaluation using observed data, J. Hydrol., 159, 305-333, 1994.

O'Connell, P. E. and Todini, E.: Modelling of rainfall, flow and mass transport in hydrological systems: an overview, J. Hydrol., 175, 3-16, 1996.

Querner, E. P.: Description and application of the combined surface and groundwater flow model MOGROW, J. Hydrol., 192, 158188, 1997.

Schuurmans, J. M., Bierkens, M. F. P., Pebesma, E. J., and Uijlenhoet, R.: Automatic prediction of high-resolution daily rainfall fields for multiple extents: the potential of operational radar, J. Hydrometeorol., accepted, 2007.

Shah, S. M. S., O'Connel, P. E., and Hosking, J. R. M.: Modelling the effects of spatial variability in rainfall on catchment response. 2. experiments with distributed and lumped models, J. Hydrol., 175, 89-111, 1991.

Wessels, H. R. A. and Beekhuis, J. H.: Stepwise procedure for suppression of anomalous ground clutter, in: COST-75 Seminar on Advanced Radar Systems, EUR 16013 EN, pp. 270-277, 1997.

Winter, T. C., Rosenberry, D. O., and Sturrock, A. M.: Evaluation of 11 equations for determining evaporation for a small lake in the North Central United States, Water Resour. Res., 31(4), $983-$ 993, 1995.

Zaadnoordijk, W. J.: Analytic expression for output reliability: Verifying automated calibration and confidence calculations of a groundwater flow simulator, Water Resour. Res., 39(12), 1351, doi:10.1029/2002WR001932, 2003. 